\title{
Wettability between Molten Slag and Dolomitic Refractory
}

\author{
Ping Shen ${ }^{1}$, Lifeng Zhang ${ }^{1}$, Yi Wang ${ }^{1}$, Seetharaman Sridhar ${ }^{2}$, Qiangqiang Wang ${ }^{1}$ \\ ${ }^{1}$ School of Metallurgical and Ecological Engineering \\ University of Science and Technology Beijing \\ Beijing 100083, China \\ ${ }^{2}$ Warwick Manufacturing Group, University of Warwick \\ Coventry, CV4 7AL, UK
}

Correspondent: Lifeng Zhang; tel.: +86-10-62332267; fax: +86-10-62332267; E-mail: zhanglifeng@ ustb.edu.cn; postal address: School of Metallurgical and Ecological Engineering, University of Science and Technology Beijing, No. 30, Xueyuan Road, Haidian District, Beijing 100083, China

\begin{abstract}
In the current study, the wettability between molten slag and dolomitic refractory materials used in the ladle during steel refining was investigated. The contact angle between molten slag and dolomitic substrate decreased with increasing temperature. The slag with lower basicity spread on the substrate more easily and penetrated deeper into the substrate. The penetration depth of slag into the refractory increased with the extension of holding time. The $\mathrm{CaO}$ in the refractory dissolved into slag which was then saturated with $\mathrm{CaO}$. The reaction between slag and substrate resulted in the formation of solid $\mathrm{Ca}_{3} \mathrm{SiO}_{5}$, which slowed down the further penetration of slag into the refractory.
\end{abstract}

KEY WORDS: contact angle; wettability; slag; basicity; penetration

\section{Introduction}

The dolomitic refractory is widely used for containment of steel melts during steelmaking and refining, especially in the production of special steels and clean steels ${ }^{[1-3]}$, due to its excellent high temperature stability, slag erosion resistance and peeling resistance ${ }^{[4]}$. Compared with $\mathrm{MgO}-\mathrm{C}$ refractory, dolomitic refractory will not cause the increase of carbon in molten steel. Besides, $\mathrm{CaO}$ in dolomitic refractory can purify the molten steel by removing inclusions from molten steel ${ }^{[5-7]}$. Based on the previous advantages, the dolomitic refractory plays an important role in the production of stainless steels. However, the application of dolomitic refractory is restricted to the hydration of free $\mathrm{CaO}^{[4,8]}$ at room temperature and the low erosion resistance of low basicity slag ${ }^{[1]}$. In MgO-based refractory, $\mathrm{MgO}$ was proved to be less reactive during the manufacture of refractory ${ }^{[5,6,9,10]}$ as well 
as during the erosion of refractory. The main erosion focuses on the reaction between slag and $\mathrm{CaO}^{[11]}$.

The consumption of refractory is one of the major costs of steel production. Compared with the hydration of $\mathrm{CaO}$ contained refractory, the erosion of refractory is the most important reason for the wear of refractory ${ }^{[12]}$. According to Cooper ${ }^{[13]}$, the erosion of oxides is not only caused by the dissolution or evaporation of the oxides, but also the penetration of liquid phase into the oxides. Penetration of slag into refractory, which is closely related to the wettability between slag and refractory, mainly through pores, grain boundaries and cracks under capillary force.

Ladle Furnace (LF) process is a widely-used secondary steel refining process. During LF process, three electrodes are used to heat the molten steel to the required temperature. By blowing argon gas, adding alloys, and adjusting slag composition, molten steel is deoxidized, desulfurized and alloyed. The erosion of lining refractory not only relates to the chemical reaction, but also some physical processes. The penetration of molten slag into refractory and then the dispersion of refractory grains into slag is one of the damage mechanisms of the refractory. Since the temperature increases during LF process, the wettability between molten slag and refractory varies. Furthermore, the slag basicity also varies during the refining of steel.

Monaghan et al. ${ }^{[14]}$ investigated the dynamic wetting of slags with different compositions on solid oxides representing inclusion phases $\left(\mathrm{Al}_{2} \mathrm{O}_{3}, \mathrm{MgAl}_{2} \mathrm{O}_{4}\right.$ and $\left.\mathrm{CaO} \cdot \mathrm{Al}_{2} \mathrm{O}_{3}\right)$, and concluded that for basic type ladle slags the plateau contact angle was independent of slag composition and for acid type slags the plateau contact angle decreased with increasing basicity. Choi and Lee ${ }^{[15]}$ conducted a number of experiments with different slag compositions and the results showed that the effect of slag basicity on the wettability depended on the slag composition. The slag basicity might have an opposite effect on the wettability in different composition regions. In the region of low $\mathrm{SiO}_{2}$ content, the slag with higher $\mathrm{CaO}$ content exhibited a smaller contact angle.

The existing researches mainly focused on the wettability between slag and single component substrate representing for inclusion. The interaction between slag and refractory substrate as well as the influence of slag basicity on the penetration were not clearly indicated. In the current study, the wettability between slag and dolomitic ladle lining refractory used for the LF refining of a stainless steel was studied. Experiments were conducted to analyze the effects of slag basicity and holding 
time on the wettability.

\section{Sample preparation}

The slag sample was taken during LF refining process in a steel plant. It was the final slag of LF refining process, which was usually considered stable in composition. It was pulverized after cooling down, and became powder containing some iron droplets. The sample was sieved through a 100 mesh sifter to remove iron droplets. After being well mixed, the slag sample was pressed into a cylinder of $0.20 \mathrm{~g}$ for each experiment.

The ladle lining refractory brick chosen for the wettability experiment was the one before service, which was completely new. The refractory brick was crushed and ground to small particles, and then the powder was tabletted into thin substrates with $30 \mathrm{~mm}$ in diameter and $3 \mathrm{~mm}$ in thickness. The substrates were sintered at $1600{ }^{\circ} \mathrm{C}$ for $2 \mathrm{~h}$. After sintering, the substrates were polished and the surface roughness of the final substrates were $0.4 \sim 0.6 \mu \mathrm{m}$.

The chemical composition of slag and refractory determined by XRF are given in Table $\mathbf{1}$ and Table 2 respectively. The refractory mainly consisted of $\mathrm{MgO}$ and $\mathrm{CaO}$, while the slag mainly consisted of $\mathrm{CaF}_{2}-\mathrm{CaO}-\mathrm{SiO}_{2}$, and both of them contained small amount of other oxides. The basicity of the slag was 2.24 . Considering the possible working condition of the refractory ${ }^{[1,16]}$, five other slags with basicity of 2.5, 2.0, 1.75, 1.5 and 1.25 as listed in Table $\mathbf{3}$ were prepared by adding certain amounts of $\mathrm{SiO}_{2}$ or $\mathrm{CaO}$.

Table 1 Chemical composition of LF slag

\begin{tabular}{ccccccccccc}
\hline Composition & $\mathrm{CaF}_{2}$ & $\mathrm{CaO}$ & $\mathrm{SiO}_{2}$ & $\mathrm{MgO}$ & $\mathrm{Al}_{2} \mathrm{O}_{3}$ & $\mathrm{CaS}$ & $\mathrm{MnO}$ & $\mathrm{Fe}_{2} \mathrm{O}_{3}$ & $\mathrm{Cr}_{2} \mathrm{O}_{3}$ & $\mathrm{TiO}_{2}$ \\
\hline Content(\%) & 13.86 & 54.79 & 24.51 & 3.60 & 1.06 & 1.23 & 0.11 & 0.26 & 0.24 & 0.31 \\
\hline
\end{tabular}

Table 2 Chemical composition of ladle lining refractory

\begin{tabular}{ccccccccccc}
\hline Composition & $\mathrm{MgO}$ & $\mathrm{CaO}$ & $\mathrm{SiO}_{2}$ & $\mathrm{Fe}_{2} \mathrm{O}_{3}$ & $\mathrm{Al}_{2} \mathrm{O}_{3}$ & $\mathrm{MnO}$ & $\mathrm{S}$ & $\mathrm{P}_{2} \mathrm{O}_{5}$ & $\mathrm{Cr}_{2} \mathrm{O}_{3}$ & $\mathrm{TiO}_{2}$ \\
\hline Content(\%) & 56.70 & 39.80 & 1.55 & 1.22 & 0.52 & 0.09 & 0.03 & 0.04 & 0.03 & 0.03 \\
\hline
\end{tabular}

Table 3 Slags with different basicity

\begin{tabular}{ccccccc}
\hline Slag & A & B & C & D & E & F \\
\hline Basicity & 2.5 & 2.24 & 2.0 & 1.75 & 1.5 & 1.25 \\
\hline
\end{tabular}




\section{Experimental setup and procedure}

The wettability is usually described by contact angle. In the current study, the sessile drop method $^{[17]}$ was employed to measure the contact angle between molten slag and dolomitic refractory. The measurement of contact angle was conducted in a horizontal tube furnace. The experimental setup is shown in Figure 1. The substrate and the slag sample were placed in the constant temperature zone of the alumina tube. Both sides of the tube were sealed by flange plates equipped with quartz glass. The temperature rose from room temperature to the desired temperature at a heating rate of $5{ }^{\circ} \mathrm{C} / \mathrm{min}$. The experiment was conducted in Ar gas (purity $99.999 \mathrm{vol} \mathrm{pct}$ ), which was purified by Ar purification device and magnesium powder at $600{ }^{\circ} \mathrm{C}$. The light of the lamp passed through the tube and the shadow of samples was recorded by a CCD camera, simultaneously the temperature and time were also recorded. The profile of the liquid drop was extracted by ellipse fitting using a software. The contact angle was obtained by drawing the tangent line of the ellipse at the three-phase contact point. In the current study, eight experiments were conducted to study the effects of slag basicity and holding time on the wettability.

After the measurement of contact angle, the samples were still protected by Ar gas till the furnace was cooled down to the room temperature. During cooling, the slag was completely pulverized. After removing the powder, the substrate was cut perpendicularly from the center, and the cross section was analyzed by SEM-EDS.

\section{Results}

\subsection{Contact angle between molten slag and dolomitic substrate}

The slag usually melts gradually with the rising of temperature in a wide range. The height of the slag decreases with the spreading of slag on the substrate. In the current study, the hemisphere point temperature is considered as the melting point of the slag, and the temperature range corresponding to five-sixths and one-third of the initial height (represented by $\mathrm{H}$ ) of slag is considered as the melting temperature range. Both the melting point and melting temperature range are empirical values that have been widely used ${ }^{[18,19]}$. The temperatures measured by this method are shown in Figure 2. The slag with higher basicity had higher melting point and wider melting temperature range. 
Once the slag melted and formed an obvious liquid phase at the three-phase point, the contact angle was defined as the initial contact angle in the current study. The initial contact angle was approximately $55^{\circ}$. Figure 3 shows the contact angle between slags with different basicity and refractory substrates. When the basicity of slag increased from 1.25 to 2.5 , the temperature corresponding to the initial contact angle increased. The slag with lower basicity had lower contact angle at the same temperature. The contact angle between the slag with lower basicity and dolomitic substrate decreased fast and finally reached a low value. According to the work done by Monaghan ${ }^{[14]}$ et al. and Choi ${ }^{[15]}$ et al., the effect of slag basicity on the contact angle might be quite different for different slag compositions. In the current study, the contact angle between slag with lower basicity and substrate was smaller, which was in consistent with Choi's result. However, the reaction product for all the slags are the same, which will be shown in the following part, the stable contact angle varied little. Figure 4 shows the contact angle between slags and refractory substrates with different holding time. After 120 minutes, the contact angle reached a stable value of approximately $5^{\circ}$.

Figure 5 shows the evolution of slag morphology at different temperatures. The slag with basicity of 2.24 melted in a wide temperature range and spread on the substrate slowly. The contact angle gradually decreased with the spreading of slag. The spreading of slag and the decrease of contact angle in the isothermal stage were much slower compared with those in the temperature rising stage. The other slags show the similar melting process, but in different temperature ranges and at different spreading rates.

\subsection{Penetration of slag into substrate}

The cross section of substrates after experiment were analyzed by SEM-EDS. As a reference, another substrate without involving in the wetting experiment was prepared in the same way. Figure 6 shows the SEM images of the two substrates. The original substrate mainly consisted of several big grains $(<150 \mu \mathrm{m})$, large amount of small grains $(\sim 7 \mu \mathrm{m})$ and the continuous phase among grains. Some pores distributed along the margin of big grains. The EDS result confirmed that both big grains and small grains were $\mathrm{MgO}$, and the continuous phase was $\mathrm{CaO}$. Small amount of impurities mainly existed in the $\mathrm{CaO}$ phase. The substrate after experiment showed similar structure. However, part of $\mathrm{CaO}$ was replaced by the penetrated slag phase. Figure 7 shows the composition distribution of the substrate. Since the slag was pulverized during cooling, only a thin slag layer stuck on the 
substrate. The composition of the slag layer above the substrate detected by EDS indicated little difference with the penetrated slag in the substrate. The typical composition of different locations presented with different color is listed in Table 4. Considering the inaccuracy of EDS for the element fluorine, the detected $\mathrm{CaF}_{2}$ content might be lower than the true value, leading to a higher content of $\mathrm{CaO}$, especially for the light grey area in Table 4. The slag penetrated into the substrate through grain boundaries, micro-cracks and pores. All the other substrates showed similar structures and compositions.

Table 4 EDS composition at different locations

\begin{tabular}{|c|c|c|c|c|c|c|c|c|c|c|}
\hline Slag basicity & & $\mathrm{CaO}$ & $\mathrm{SiO}_{2}$ & $\mathrm{Al}_{2} \mathrm{O}_{3}$ & $\mathrm{MgO}$ & $\mathrm{Fe}_{2} \mathrm{O}_{3}$ & $\mathrm{CaF}_{2}$ & $\mathrm{TiO}_{2}$ & $\mathrm{MnO}$ & $\mathrm{Cr}_{2} \mathrm{O}_{3}$ \\
\hline & Light Grey & 82.78 & 15.34 & 0.27 & 0.47 & 0 & 0.44 & 0.12 & 0.37 & 0.21 \\
\hline \multirow[t]{2}{*}{2.24} & Grey & 96.47 & 0.32 & 0.14 & 1.74 & 0.53 & 0.15 & 0.25 & 0.29 & 0.11 \\
\hline & Dark grey & 2.17 & 0.16 & 1.13 & 91.96 & 1.82 & 0.77 & 0 & 0.58 & 1.42 \\
\hline
\end{tabular}

Since the penetration of slag into refractory substrate was hardly uniform along the interface, no remarkable penetration layer could be observed, the line scanning perpendicular to the surface of the substrate could hardly accurately illustrate the penetration depth of the slag. In the current study, several equally spaced locations at the interface between slag and substrate were chosen to perform EDS composition mapping. The scanning started from the interface to the inner of the substrate, as shown in Figure 8. Then, the result of the EDS mapping was converted to intensity data according to the gray value of scanning point. The distribution of elements were finally represented in the form of oxide, which is shown in Figure 9. It indicated that the magnesia did not dissolve into the slag, and the distribution of silica and magnesia could be used to represent the slag and substrate respectively. The outline of the magnesia characterized by red line in Figure 9(c) represented the interface between the slag and the substrate. Thus, the distribution of silica in Figure 9(a) was separated into two parts, only the silica below the interfacial line was the penetrated slag, shown in Figure 9(c), and that above the interfacial line was the slag stuck on the surface.

Figure 10 and Figure 11 show the distribution of silica in the substrate after experiment. Slag F spread out of the margin of the substrate in a short time, so that only small amount of slag left on the substrate, and no obvious penetration was observed. Both of the substrates contacted with slag D and E cracked during cooling, mainly caused by the penetration of slag and the different expansion 
coefficients of the three phases listed in Table 4. The substrate contacting with slag D was seriously broken that no such intact cross section of the substrate could be prepared to show the element distribution.In all experiments, the silica-rich area didn't locate at the center where the slag contacted with the substrate during all the experiment time. Instead, the silica concentrated in one ring between the center and the margin of the contact area. Figure 12 illustrates the schematic penetration phenomenon.

\section{Interaction between slag and substrate}

After the measurement of contact angle, the surface of the substrate and the pulverized slag together with the original sample were detected by XRD and the results are shown in Figure 13. There were no big differences between the pulverized slag and the original slag. The main composition in the slag was $\gamma-\mathrm{Ca}_{2} \mathrm{SiO}_{4}$. The phase transformation of $\mathrm{Ca}_{2} \mathrm{SiO}_{4}$ during cooling was the main reason for the pulverization of slag ${ }^{[20]}$. Compared with the original substrate, the composition of slag stuck on the substrate was quite different from that of the pulverized slag. Except for $\mathrm{MgO}$ and $\mathrm{CaO}, \mathrm{Ca}_{3} \mathrm{SiO}_{5}$ phase which was formed above $1250{ }^{\circ} \mathrm{C}$ was generated in the substrate during the experiment according to Equation 1. The chemical reaction mainly occurred at the interface. $\mathrm{CaO}$ in the dolomitic substrate provided the source for the formation of $\mathrm{Ca}_{3} \mathrm{SiO}_{5}$, meanwhile, $\mathrm{MgO}$ promoted the formation of $\mathrm{Ca}_{3} \mathrm{SiO}_{5}{ }^{[21]}$.

$$
\mathrm{Ca}_{2} \mathrm{SiO}_{4}+\mathrm{CaO}=\mathrm{Ca}_{3} \mathrm{SiO}_{5}
$$

The mass of slag in each experiment was $0.2 \mathrm{~g}$. Taking the main compositions in the slag, i.e. $\mathrm{CaF}_{2}-\mathrm{CaO}-\mathrm{SiO}_{2}-\mathrm{MgO}-\mathrm{Al}_{2} \mathrm{O}_{3}$, into consideration, the equilibrium phases are calculated by Factsage 7.0. Most of $\mathrm{CaO}$ is transformed to complex compounds or dissolved into liquid slag, while part of $\mathrm{MgO}$ in the slag is kept unreacted, as shown in Figure 14. When the slag contacts with the dolomitic substrate, $\mathrm{CaO}$ and $\mathrm{MgO}$ in the substrate may react with or dissolve into the liquid slag. Assume that $2.0 \mathrm{~g}$ slag reacts with $5.0 \mathrm{~g}$ dolomitic, and the dolomitic substrate only contains $\mathrm{MgO}$ and $\mathrm{CaO}$. The ration of $\mathrm{CaO}$ and $\mathrm{MgO}$ in dolomitic substrate participating in the reaction between slag and substrate are shown in Figure 15. $\mathrm{MgO}$ in the substrate is inert under the experiment condition. only $\mathrm{CaO}$ in the substrate can react with or dissolve into the slag, which means that the spreading and penetration of slag are not only a physical process but also a chemical process. Except for the traditional channels, such as grain boundaries, micro cracks and pores, the liquid slag may penetrate 
into the substrate through the channel where $\mathrm{CaO}$ exists once $\mathrm{CaO}$ dissolves into the liquid slag.

\section{Factors affecting the penetration depth}

\subsection{Slag basicity}

As is mentioned above, there were large grains, irregular pores and micro-cracks in the substrate, providing channels for the penetration of slag. The slag penetrated into the substrate much deeper at the location with more pores. However, the distribution of pores was hardly uniform. As a result, the largest penetration depth was random and the amount of the penetrated slag was small at the deepest penetrated location. In the current study, considering the SEM images and the scanning intensity, the largest penetration depth of the slag was only focused on the silica-rich area, not including the trace content at deeper area. The red line shown in Figure $\mathbf{1 0}$ and Figure $\mathbf{1 1}$ indicates the interface between slag and substrate, and is defined as the zero penetration depth. The largest penetration depth in the two figures are marked by bold white line. The largest penetration depth of the four substrates are shown in Figure 16, indicating the relationship between slag basicity and penetration depth. The slag with lower basicity had larger penetration depth. Similar results were reported by $\mathrm{Luz}^{[22]}$. In the current study, the largest penetration depth was $178 \mu \mathrm{m}$ for the slag with basicity of 1.5 .

The slag penetrated into substrate mainly through grain boundaries, micro cracks and pores. The capillary force was the driven force for the penetration of slag. The wettability between molten slag and substrate was one of the important factors that affecting the capillary force. Slag with lower basicity wet the substrate more easily (Figure 3). Therefore, a larger penetration depth could be obtained.

$\mathrm{CaO}$ coming from the substrate might dissolve into the liquid slag, providing the channel for the penetration of slag. The capacity for the dissolution of $\mathrm{CaO}$ depended on the $\mathrm{CaO}$ saturability of the slag. Figure 17 shows the saturated $\mathrm{CaO}$ content in all liquid slags. There were no big differences between the different slags. Since the slag with higher basicity contained more $\mathrm{CaO}$, fewer would come from the substrate. On the contrary, for the slag with lower basicity, more $\mathrm{CaO}$ coming from the substrate would dissolve into the liquid slag, providing extra penetration channel and causing the increase of penetration depth. By the way, the increase of temperature accelerated the dissolution of $\mathrm{CaO}$ from substrate. 


\subsection{Contact time}

Figure 18 shows the relationship between holding time and penetration depth. With the increase of holding time, the penetration depth increased. $\mathrm{Heo}^{[23]}$ et al. studied the reactive wetting phenomena of $\mathrm{MgO}-\mathrm{C}$ refractories in contact with $\mathrm{CaO}-\mathrm{SiO}_{2}$ slag and concluded that an intrinsic contact angle existed during initial $4 \mathrm{~s}$ without chemical reaction. Park ${ }^{[24]}$ et al. also indicated that during the initial short period, the dissolution of oxide into slag was neglected. In the current study, when the newly contact area was covered by the slag, the initial penetration was caused by the flow of slag through grain boundaries, micro cracks and pores without any reaction. The initial penetration finished in a short time, within which the dissolution of the solid oxide into the slag was relatively slow ${ }^{[25]}$. The following penetration was accompanied with the dissolution of $\mathrm{CaO}$ until the slag was saturated with $\mathrm{CaO}$. Once the $\mathrm{Ca}_{3} \mathrm{SiO}_{5}$ was generated, the solid phase under the experiment temperature would prevent the flow of the original slag. The further penetration of slag was caused by diffusion. Equation 2 shows ideal penetration depth for an unreactive system. Both the penetration of slag according to Equation 2 or the diffusion of slag were closely related to the time, the increase of time lead to the deeper penetration. Pretending that other parameters are replaced by a penetration rate k, as shown in Equation 3. The penetration rate k is approximately $58 \mu \mathrm{m} / \mathrm{h}^{0.5}$ according to Figure 18. Meanwhile, the $\mathrm{CaO}$ also diffused to the slag phase. In Figure 12, the silica-rich area provided a relative big interfacial area between the penetrated slag and the dolomitic substrate for the diffusion of $\mathrm{CaO}$. As a result, the silica-rich area in the substrate was also the area of slag saturated with $\mathrm{CaO}$ above the substrate.

$$
\begin{aligned}
& X=\sqrt{\frac{r \gamma \cos \theta}{2 \eta} t} \\
& X=k \sqrt{t}
\end{aligned}
$$

where $X$ is the penetration depth, $r$ is the radius of the capillary channel, $\gamma$ is the surface tension of the liquid phase, $\theta$ is the contact angle, $\eta$ is the viscosity and $\mathrm{t}$ is the penetration time.

Although the contact time between slag and substrate in the center was longer than that in the margin, the initial contact in the center caused the primary formation of $\mathrm{Ca}_{3} \mathrm{SiO}_{5}$, even before the melting of slag. Thus the shallow penetration depth in the center was observed.

\section{Conclusions}


(1) In the current study, the contact angle continuously decreased with the increase of temperature. The stable contact angle between the substrate and the slag saturated with $\mathrm{CaO}$ at $1566{ }^{\circ} \mathrm{C}$ was approximately $5^{\circ}$.

(2) $\mathrm{MgO}$ in the dolomitic substrate did not react with or dissolve into slag for all slags in the current study. The $\mathrm{CaO}$ in the dolomitic substrate might react with or dissolve into liquid slag. The substrate could provide extra penetration channel once the $\mathrm{CaO}$ dissolved into liquid slag, accelerating the penetration of slag. The $\mathrm{CaO}$ in the substrate also reacted with slag and formed $\mathrm{Ca}_{3} \mathrm{SiO}_{5}$, preventing the penetration of slag.

(3) Slag with lower basicity started to wet the substrate at lower temperature, and the contact angle decreased fast in a narrow temperature range in the temperature rising stage. The final stable contact angle showed no big differences between all slags, i.e. approximately $5^{\circ}$. The strong reactive wetting between slag with lower basicity and dolomitic refractory was one of the reason for the fast decrease of the contact angle.

(4) Slag with lower basicity had bigger capacity for the dissolution of $\mathrm{CaO}$, thus achieved larger penetration depth in the substrate. The largest penetration depth was $178 \mu \mathrm{m}$ for the slag with basicity of 1.5 .

(5) With the increase of holding time from $1 \mathrm{~h}$ to $3 \mathrm{~h}$, the contact angle between slag and substrate decreased from $10.5^{\circ}$ to $5.0^{\circ}$, and the penetration depth of slag increased from $55 \mu \mathrm{m}$ to $100 \mu \mathrm{m}$.

\section{Acknowledgements}

The authors are grateful for support from the National Science Foundation China (Grant No. 51274034, No. 51334002, No.51404019 and No.51504020), Beijing Key Laboratory of Green Recycling and Extraction of Metals (GREM), the Laboratory of Green Process Metallurgy and Modeling $\left(\mathrm{GPM}^{2}\right)$ and the High Quality Steel Consortium (HQSC) at the School of Metallurgical and Ecological Engineering at University of Science and Technology Beijing (USTB), China. Correspondence author: Lifeng Zhang, E-mail:zhanglifeng@ustb.edu.cn

\section{References}

[1] Y. Liang, Y. Li. Slag resistance of MgO-CaO bricks[J]. Refractories, 2009, 43(4): 263-266.

[2] X. Zhong. Looking ahead-A new generation of high performance refractory ceramics[J]. China's 
Refractories, 2002, 11(3): 3-13.

[3] W. Dai, J. Yu. Refractory for clean steel making[J]. Journal of Materials and Metallurgy, 2003, 2(1): 3-9.

[4] Z. Li, S. Zhang, W. E. Lee. Improving the hydration resistance of lime-based refractory materials[J]. International Materials Reviews, 2008, 53(1): 1-20.

[5] H. Zhang, H. Zhao, J. Chen, et al. Defect study of $\mathrm{MgO}-\mathrm{CaO}$ material doped with $\mathrm{CeO}_{2}[\mathrm{~J}]$. Advances in Materials Science and Engineering, 2013, 10(4): 1-5.

[6] M. Chen, C. Lu, J. Yu. Improvement in performance of $\mathrm{MgO}-\mathrm{CaO}$ refractories by addition of nano-sized $\mathrm{ZrO}_{2}[\mathrm{~J}]$. Journal of the European Ceramic Society, 2007, 27(16): 4633-4638.

[7] B. Huang, W. Zhang, H. Gu, et al. Resistance of $\mathrm{MgO}-\mathrm{CaO}$ unburned brick to refining slag[J]. Journal of Iron and Steel Research, 2004, 16(1): 10-14.

[8] F. Kashaninia, H. Sarpoolaky, A. R. Bagheri, et al. Improving hydration resistance of magnesia-doloma refractories byiron oxide addition[J]. Iranian Journal of Materials Science and Engineering, 2011, 8(4): 34-40.

[9] A. G. T. Martinez, M. A. Camerucci, A. L. Cavalieri, et al. Sintering behavior of periclase-doloma refractory mixes[J]. Journal of the European Ceramic Society, 2009, 29(4): 581-586.

[10] G. Qiu, C. Yue, X. Li, et al. Preparation and characterization of regenerated MgO-CaO refractory bricks sintered under different atmospheres[J]. International Journal of Minerals Metallurgy and Materials, 2014, 21(12): 1233-1240.

[11] X. L. Coq, B. Dupré, C. Gleitzer, et al. Slag corrosion of dolomite-carbon refractories[J]. Steel Research, 1990, 61(12): 593-597.

[12] D. N. Boccaccini, M. Cannio, M. Romagnoli, et al. The pO-index and R ratio gap methods for the assessment of corrosion risk in refractory materials in contact with glass melts[J]. Journal of the American Ceramic Society, 2010, 93(5): 1355-1363.

[13] A. R. Cooper. Kinetics of refractory corrosion, in Proceedings of the educational symposium on refractories in sagging environments: Ceramic engineering and science proceedings1981, John Wiley \& Sons, Inc. 1063-1089.

[14] B. J. Monaghan, H. Abdeyazdan, N. Dogan, et al. Effect of slag composition on wettability of oxide inclusions[J]. ISIJ International, 2015, 55(9): 1834-1840.

[15] J. Y. Choi, H. G. Lee. Wetting of solid $\mathrm{Al}_{2} \mathrm{O}_{3}$ with molten $\mathrm{CaO}-\mathrm{Al}_{2} \mathrm{O}_{3}-\mathrm{SiO}_{2}[\mathrm{~J}]$. ISIJ International, 2003, 43(9): 1348-1355.

[16] S. Li, Z. Jiang, Z. Huang, et al. Effect of refining slag basicity on inclusions in 304 stainless steel[J]. Iron and Steel, 2010, 45(12): 26-29.

[17] N. Eustathopoulos, M. G. Nicholas, B. Drevet. Wettability at high temperatures[M]. Pergamon, 1999.

[18] X. Liang, Y. Jin, Y. Wang. Effect of additives on melting point and viscosity of RH refining slag[J]. Open Materials Science Journal, 2011, 5(1): 9-14.

[19] H. Wang, G. Li, B. Li, et al. Effect of $\mathrm{B}_{2} \mathrm{O}_{3}$ on melting temperature of CaO-based ladle refining slag[J]. Journal of Iron \& Steel Research International, 2010, 17(10): 18-22.

[20] R. T. d. Cruz, S. R. Bragança. Evaluation of the protective $\mathrm{C}_{2} \mathrm{~S}$ layer in the corrosion process of doloma-C refractories[J]. Ceramics International, 2015, 41(3, Part B): 4775-4781.

[21] X. Liu, Y. Li, N. Zhang. Influence of $\mathrm{MgO}$ on the formation of $\mathrm{Ca}_{3} \mathrm{SiO}_{5}$ and $3 \mathrm{CaO} \cdot 3 \mathrm{Al}_{2} \mathrm{O}_{3} \cdot \mathrm{CaSO}_{4}$ minerals in alite-sulphoaluminate cement $[\mathrm{J}]$. Cement \& Concrete Research, 2002, 32(7): 1125-1129.

[22] A. P. Luz, F. C. Leite, M. A. M. Brito, et al. Slag conditioning effects on MgO-C refractory corrosion performance[J]. Ceramics International, 2013, 39(7): 7507-7515. 
[23] S. H. Heo, K. Lee, Y. Chung. Reactive wetting phenomena of $\mathrm{MgO}-\mathrm{C}$ refractories in contact with $\mathrm{CaO}-\mathrm{SiO}_{2}$ slag[J]. Transactions of Nonferrous Metals Society of China, 2012, 22(35): 870-875.

[24] J. Park, K. Lee, J. J. Pak, et al. Initial wetting and spreading phenomena of a $\mathrm{CaO}-\mathrm{SiO}_{2}$ liquid slag on $\mathrm{MgO}$ substrates[J]. Transactions of the Iron and Steel Institute of Japan, 2014, 54(9): 2059-2063.

[25] Y. V. Sveshkov, V. A. Kalmykov, V. G. Borisov, et al. Wetting of refractories of the CaO-MgO system by slags[J]. Refractories, 1978, 19(9-10): 655-659. 


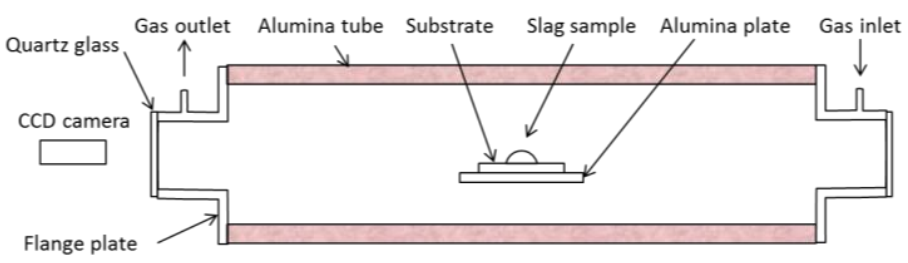

(a) Front view

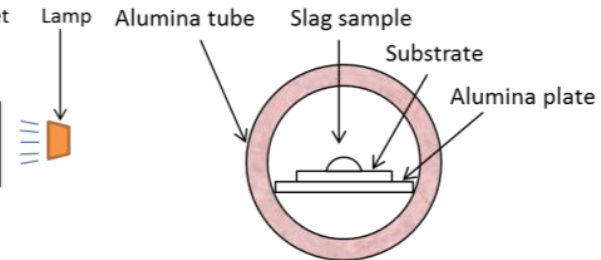

(b) Side view

Fig.1 Experimental setup

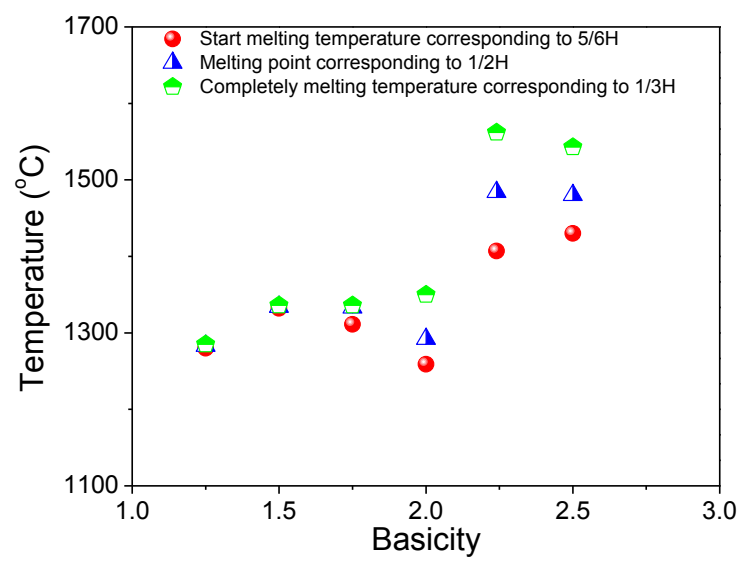

Fig. 2 Melting temperature of slags with different basicity

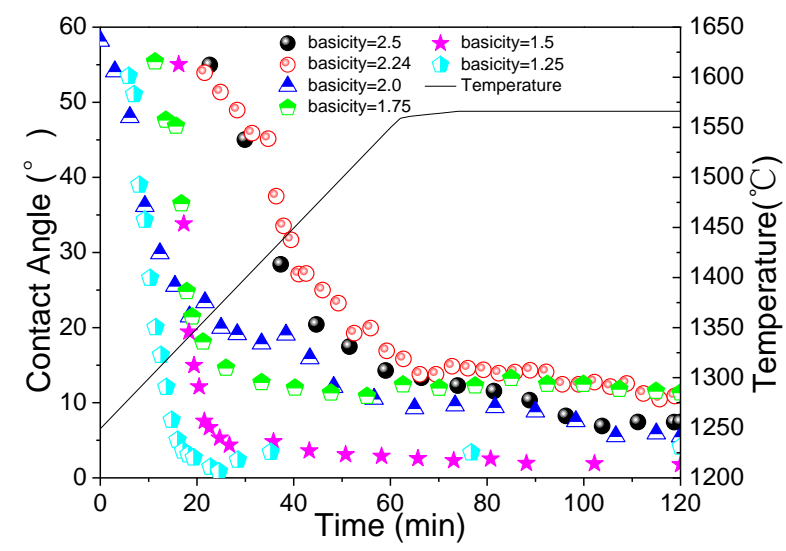

Fig. 3 Contact angle between refractory and slags with different basicity

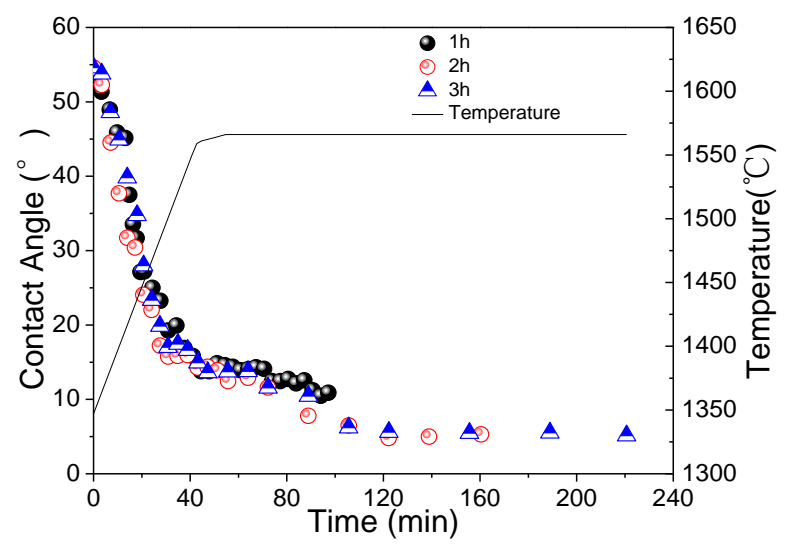

Fig. 4 Contact angle between refractory and slags with different holding times 


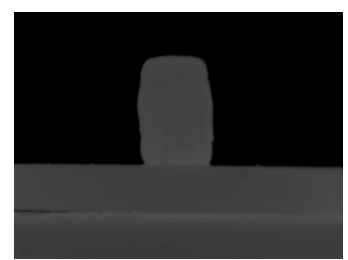

(a) $1200^{\circ} \mathrm{C}$

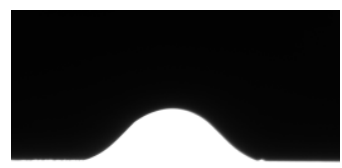

(d) $1500^{\circ} \mathrm{C}$

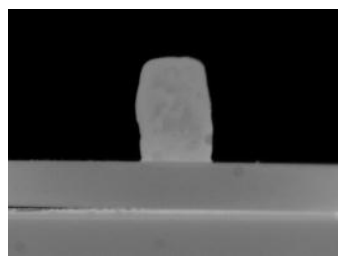

(b) $1300^{\circ} \mathrm{C}$

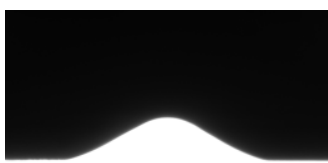

(e) $1550^{\circ} \mathrm{C}$

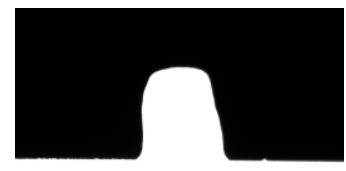

(c) $1400^{\circ} \mathrm{C}$

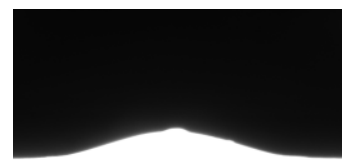

(f) $1566^{\circ} \mathrm{C}$

Fig. 5 Morphology of the slag with the basicity of 2.24 at different temperatures

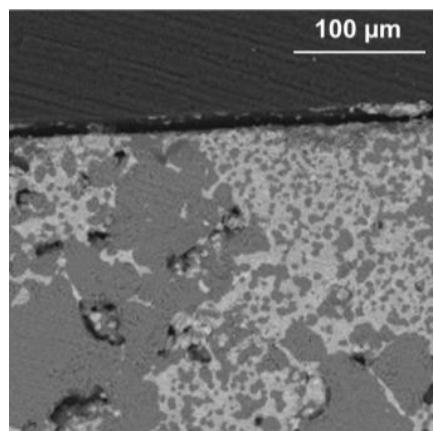

(a) Without being involved in the wetting experiment

Fig. 6 SEM image of the substrate

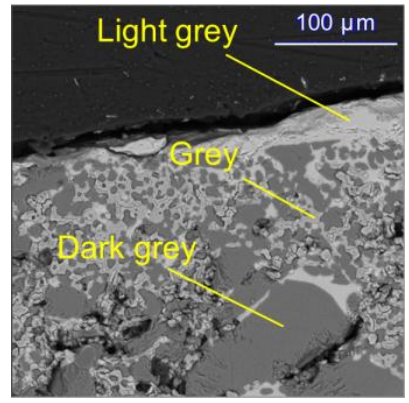

$\mathrm{Mg}$

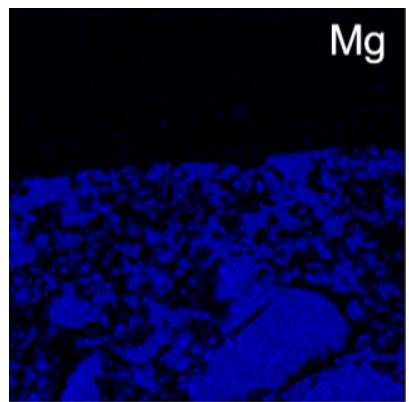

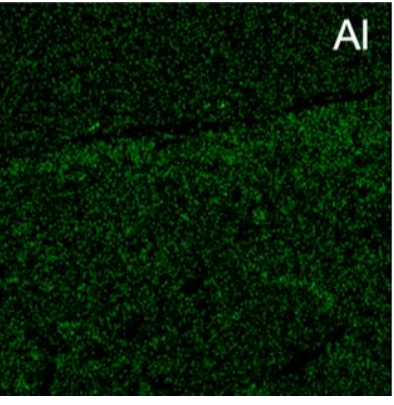

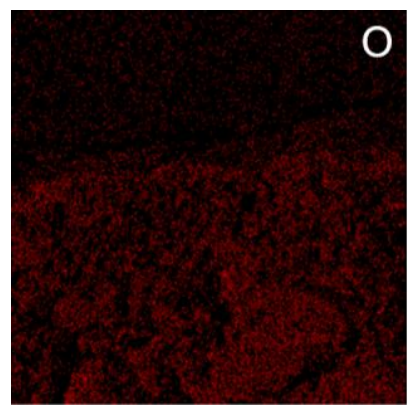

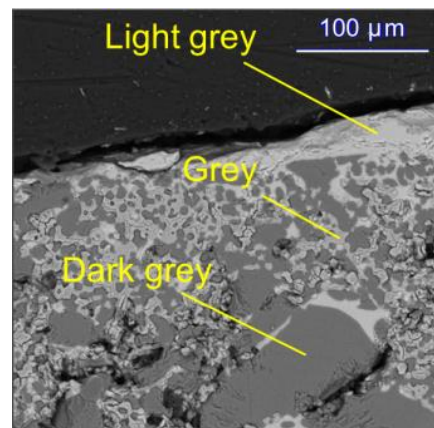

(b) Involved in the wetting experiment
$\mathrm{Ca}$

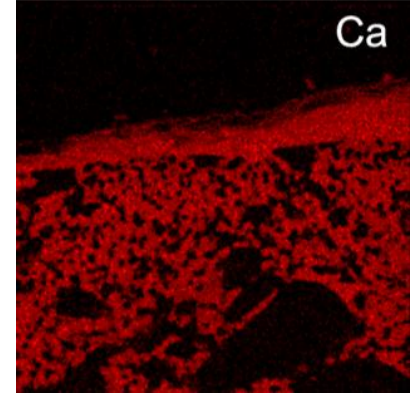

$\mathrm{Si}$

Fig. 7 Composition mapping of the cross section of one substrate 


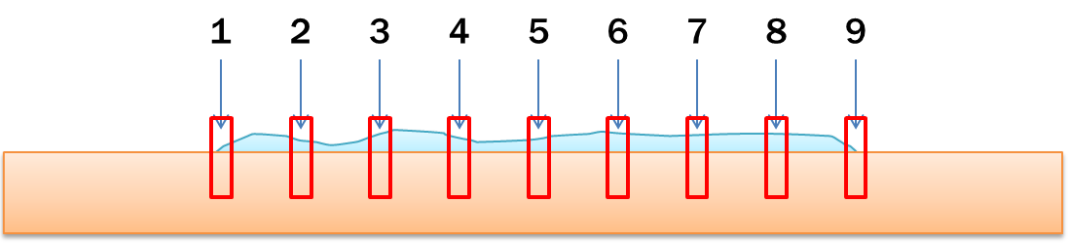

Fig. 8 Schematic of the scanning area

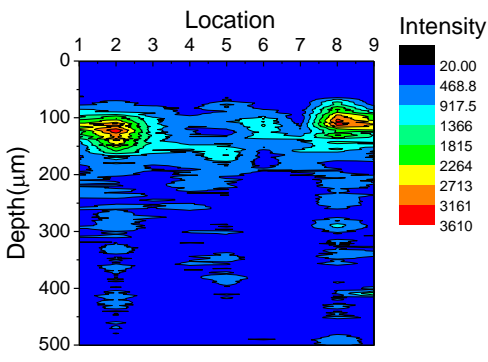

(a) Silica

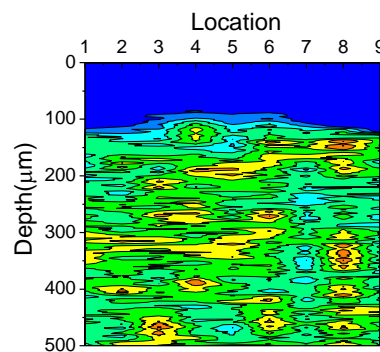

(b) Magnesia

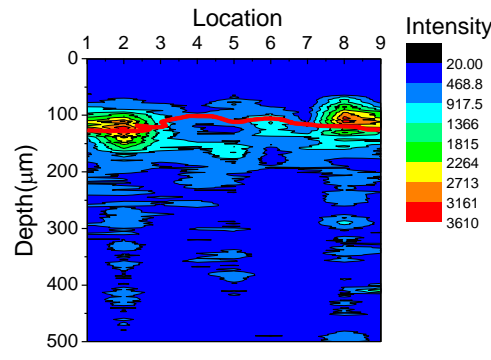

(c) Boundary of the penetrated slag characterized by silica

Fig. 9 Distribution of silica and magnesia

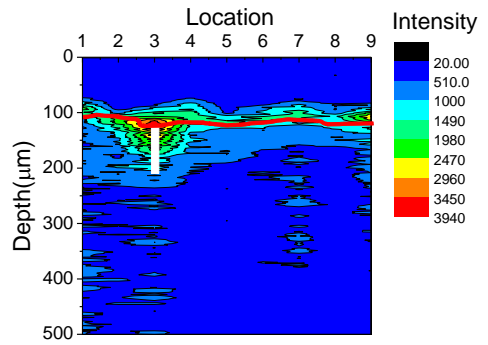

(a) Basicity $=2.5$

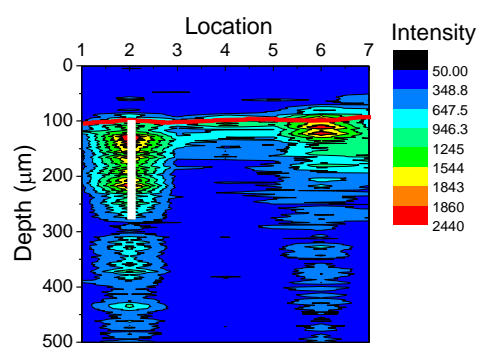

(d) Basicity $=1.5$

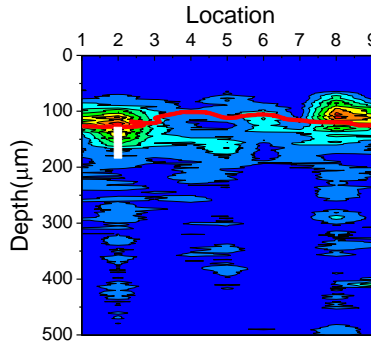

(b) Basicity $=2.24$

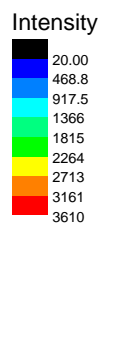

Intensity
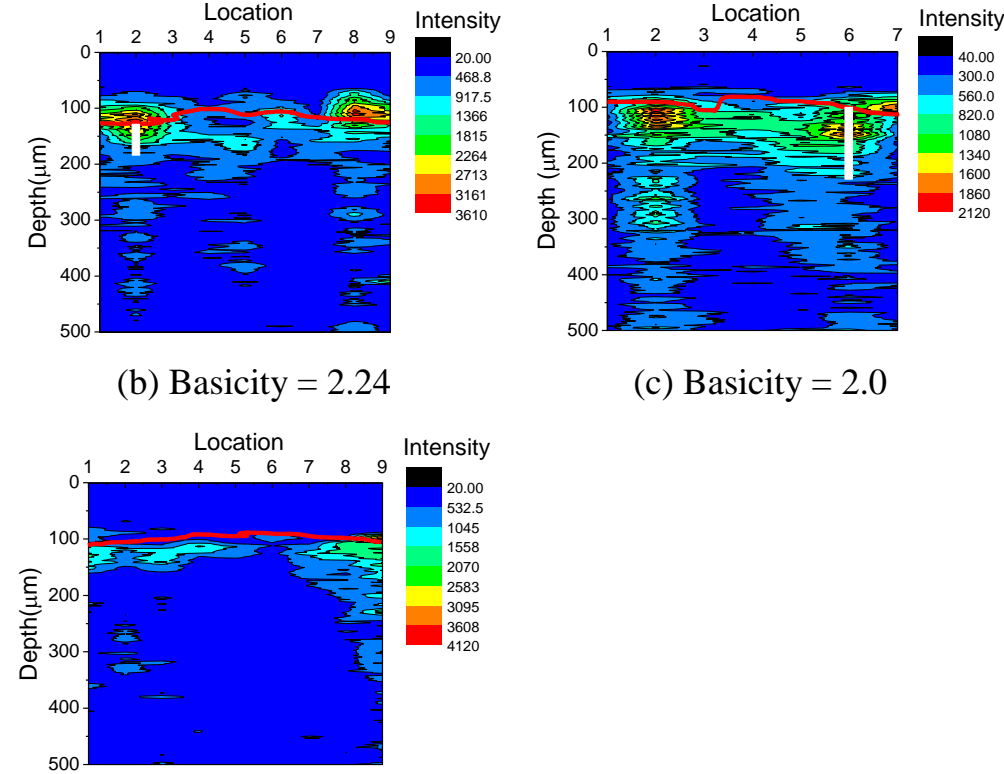

(c) Basicity $=2.0$

Fig. 10 Penetration of slag with different basicity into refractory characterized by silica

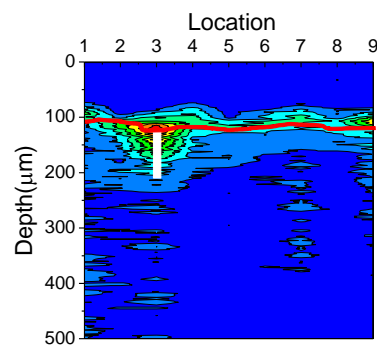

(a) $1 \mathrm{~h}$

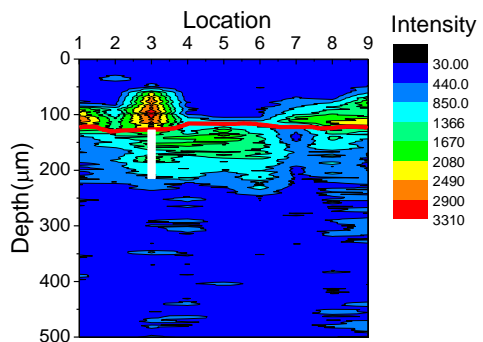

(b) $2 \mathrm{~h}$

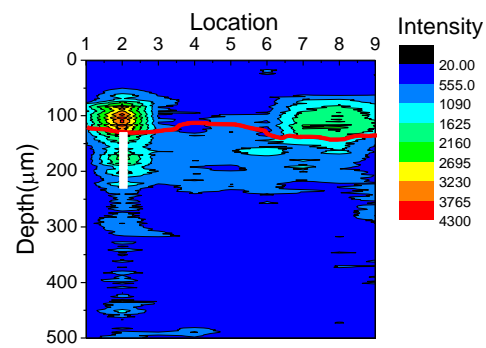

(c) $3 \mathrm{~h}$

Fig. 11 Penetration of slag into substrate with different holding times characterized by silica 


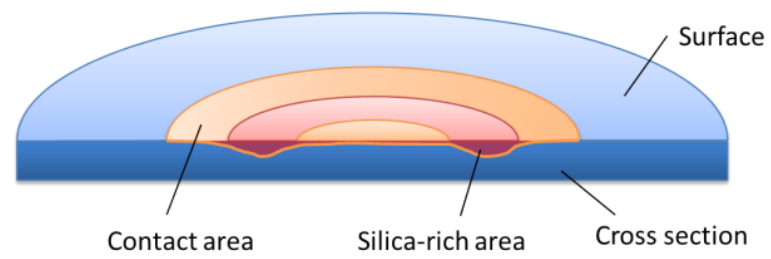

Fig. 12 Schematic of the penetration area

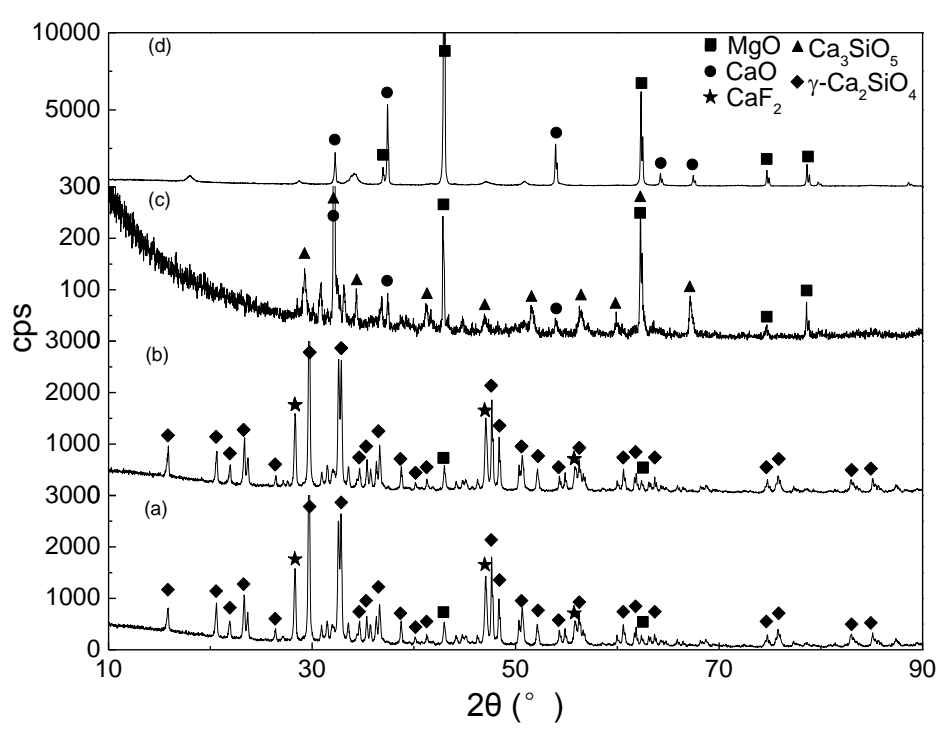

$\begin{array}{lll}\text { (a) slag before experiment } & \text { (b) slag after experiment }\end{array}$

$\begin{array}{lll}\text { (c) substrate after experiment } & \text { (d) substrate before experiment }\end{array}$

Fig. 13 XRD result of substrates and slags

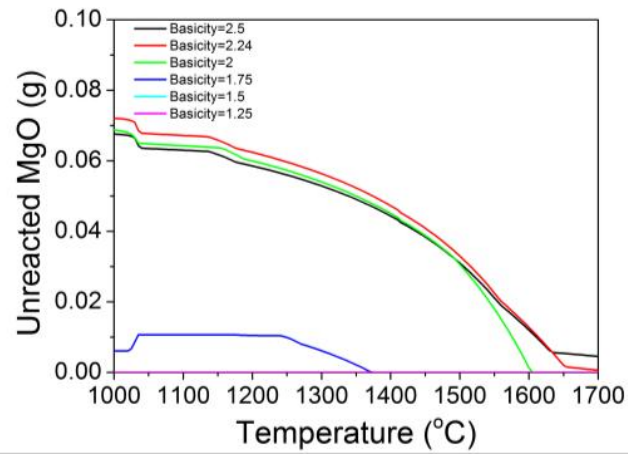

Fig. 14 Unreacted $\mathrm{MgO}$ in the slag

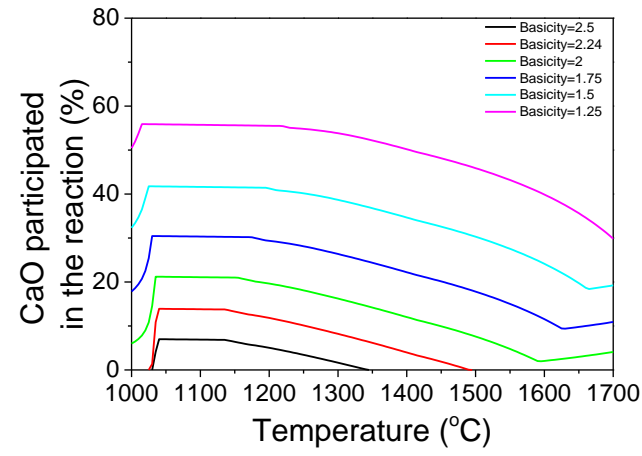

(a) $\mathrm{CaO}$

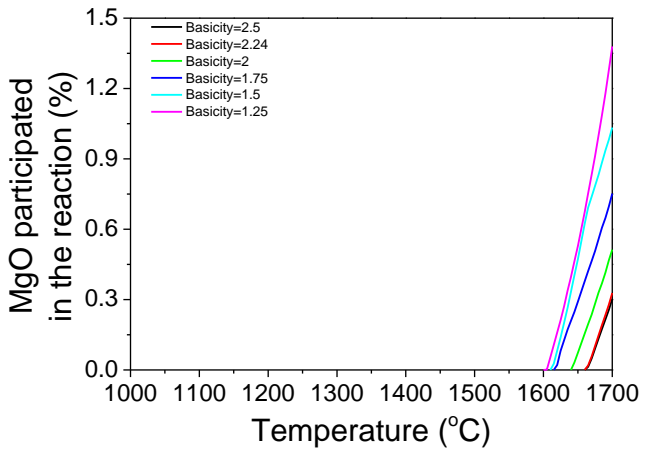

(b) $\mathrm{MgO}$

Fig. $15 \mathrm{CaO}$ and $\mathrm{MgO}$ in the substrate participating in the reaction between slag and substrate 


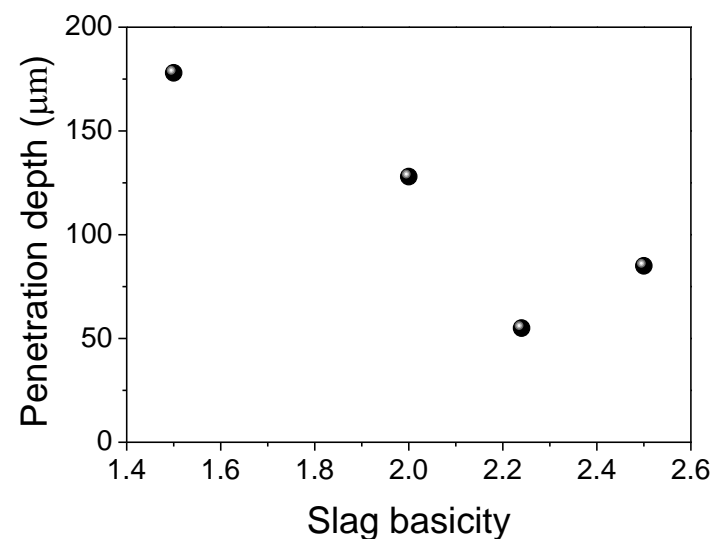

Fig. 16 Penetration depth of the slag with different basicity

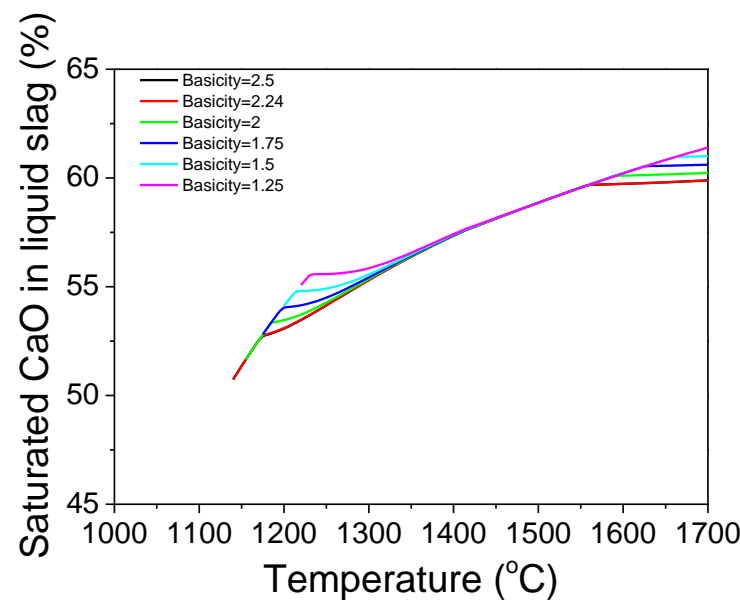

Fig. 17 Variation of saturated $\mathrm{CaO}$ in liquid slag

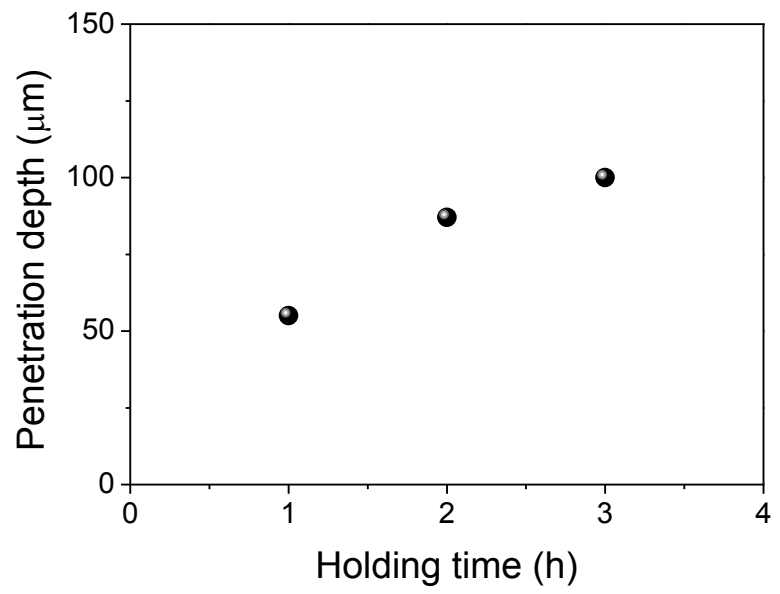

Fig. 18 Penetration depth of the slag with different holding times 